\title{
Editorial
}

\section{Remembering Obaid - One Year Later}

Obaid Siddiqi passed away on July 26, 2013, succumbing to injuries from an accident in Bangalore.

In more than half a century of work in India, Obaid built institutions and inspired many young minds. The Department of Biological Sciences (DBS) at the Tata Institute of Fundamental Research (TIFR), Mumbai, and the National Centre for Biological Sciences (NCBS), Bangalore, stand today as the finest examples of his vision and approach to science. In the process, he became the tallest (literally as well) Indian biologist of his generation, yet he remained modest, friendly and scientifically intense in his association with his peers and students.

At the DBS, TIFR, then known as the Molecular Biology Unit, Obaid pioneered the study of neurogenetics in India using the fruit fly, Drosophila melanogaster, as a model organism. Obaid was closely connected to the stars of bacterial and phage genetics. Returning from a sabbatical with one of them, Seymour Benzer at Caltech, he pushed the transformation of the Molecular Biology Unit into a new area. Drosophila neurogenetics as a field was born in the 1970s with the idea of identifying mutants that affected neural function and behaviour. Obaid took up the challenge of using the fruit fly as a genetic system to understand chemosensory behaviour. Using elegant behavioural and electrophysiological assays, his group identified the very first set of taste and olfactory mutants in Drosophila, which have subsequently helped understand the complexity of chemosensory perception in insects. In NCBS he went on to develop a group that studied learning and memory in the context of olfactory behaviour. These studies in a relatively simple organism have implications for understanding brain function at all levels.

When we decided to organize this Special Section of the Journal of Biosciences for Obaid's first death anniversary, many of his friends readily agreed despite earlier contributions to the Journal of Neurosciences issue in 2012 on Obaid's 80th birthday. The collection of articles is indeed impressive and a testament to his science and his popularity with people across generations.

We start with Maurice Fox's brief "Commentary" on how biology came to TIFR, and follow this with temperature-sensitive paralytic mutants (Ganetzy and $\mathrm{Wu}$ ), odorant receptors (Ray et al.), taste neuron projections (Kwon et al.), air-puff-stimulated flight circuit (Sadaf and Hasan), Pdf clock mutant (Seki and Tanimura), and Drosophila-derived insights into brain development and disease (Reichert).

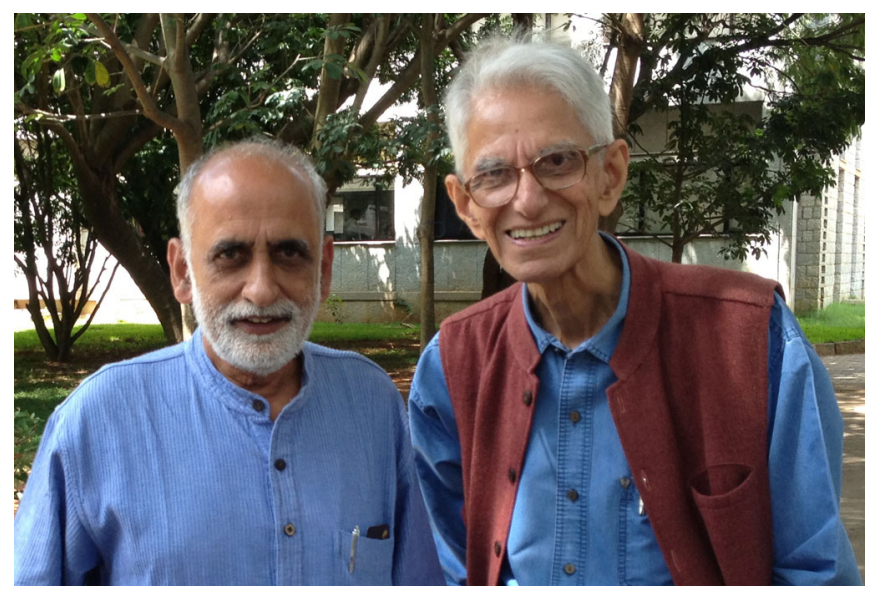

KS Krishnan and Obaid Siddiqi 
Obaid was a mentor and an inspiration for the three of us, either directly or indirectly. He showed us how science is done without shouting from rooftops, and his death remains a personal loss to each of us.

During the last days of this Special Section, Obaid's long-time associate and a friend to the three of us, KS Krishnan, also passed away suddenly. But KSK contributed to this tribute by reading all invited articles and providing his comments. He did this on the weekend prior to his death. We owe our gratitude to KSK and mourn this loss to the Indian biologist community. So long, dear friend. We hope the reader will enjoy this labour of love.

Shahid JAmEel $^{1, *}$, Utpal BanerjeE ${ }^{2}$ and $\mathrm{K}_{\text {ViJayraghavan }}{ }^{3}$

${ }^{1}$ Wellcome Trust/DBT India Alliance, Hyderabad, India

${ }^{2}$ University of California at Los Angeles, USA

${ }^{3}$ National Centre for Biological Sciences, Bangalore, and Department of Biotechnology, New Delhi, India

*Corresponding author (Email, jameelshahid@gmail.com) 